\title{
A política de habitação rural e o desenvolvimento da agricultura familiar
}

Oscar José Rover

Universidade Federal de Santa Catarina (UFSC)
Paulo Roberto Munarini

Universidade Comunitária da Região de Chapecó (Unochapecó)

\section{A política de habitação rural e o desenvolvimento da agricultura familiar}

Resumo: Este artigo analisa a contribuição do Programa Nacional de Habitação Rural (PNHR) para o desenvolvimento de territórios predominantemente rurais. A partir do estudo de sua implementação na região Oeste Catarinense, ponder sobre os avanços e as restrições desta política social. Para as análises realizadas procedeu-se a uma revisão de literatura, à busca de documentação sobre a política e sua implementação na região estudada, bem como a entrevistas com lideranças e agricultores demandantes e beneficiados por uma casa nova ou reforma. Verificou-se que o PNHR cria uma oportunidade para as famílias rurais descapitalizadas construírem ou reformarem sua casa, apesar de ser ainda restrita a sua abrangência para o conjunto dessas famílias. A reformulação do programa, reduzindo exigências financeiras e para operação dos créditos, pode oportunizar que maior número de famílias dele se beneficie, com impacto social positivo no desenvolvimento regional.

Palavras-chave: política social, habitação, desenvolvimento rural, agricultura familiar.

\section{Rural Housing Policy and the Development of Family Farming}

Abstract: This article analyzes the contribution of the National Rural Housing Program (PNHR) to the development of predominantly rural territories. Based on the study of their implementation in Western Santa Catarina, it looks at the advances and limitations of this social policy. A review of the relevant literature was conducted as well as a search of documents about the policy and its implementation in the region. Interviews were conducted with local leaders and farmers who requested and or were benefitted by a new house or the restoration of an existing one. It found that the PNHR created an opportunity for rural families without access to capital to build or restore their home, despite its scope being restricted to these families. A reformulation of the program, to reduce financial demands and credit operations could allow a larger number of families to benefit, with a positive social impact on regional development.

Key words: social policy, housing, rural development, family farming. 


\section{Introdução}

O presente trabalho analisa a política de habitação rural brasileira, através do estudo de sua implementação em uma região predominantemente rural, o Oeste Catarinense. O setor habitacional do Brasil há muito tempo é afetado pela falta de moradia, tanto em territórios urbanos como nos rurais. Na região Oeste de Santa Catarina não é diferente, sendo que nos territórios rurais, especialmente aqueles mais distantes dos maiores centros urbanos, tem havido historicamente menor oferta de serviços e políticas para seu desenvolvimento. Como exemplo disto, pode-se citar a maior dificuldade relativa dos territórios rurais para acesso à telefonia, serviços de transporte, habitação, água encanada, internet, entre outros. Devido à menor densidade demográfica dos territórios rurais, é menos rentável a qualquer empresa, seja privada ou estatal, oferecer serviços nesses territórios.

Em 2003, o Governo Federal iniciou o Programa Nacional de Habitação Rural (PNHR), com objetivo de reduzir o histórico déficit habitacional dos territórios rurais, oferecendo acesso facilitado à política social de habitação rural por parte dos agricultores familiares em condições socioeconômicas mais vulneráveis. Este programa tem produzido resultados relevantes, especialmente na região Sul do Brasil. Mas, mesmo nessa região, foram identificados importantes fatores que limitam seu avanço, apesar de ali se situarem os agricultores familiares mais estruturados e organizados do país (SCHNEIDER; CAZELLA; MATTEI, 2004; JORNALDACAIXA, 2009) e onde se localizam a maioria dos municípios com conselhos e fundos de habitação (IBGE, 2008).

$\mathrm{O}$ acesso a novas condições de moradia é um fator de melhoria da qualidade de vida das famílias agricultoras, podendo causar um impacto positivo sobre dinâmicas de desenvolvimento rural que se venha a propor. A descapitalização que a agricultura familiar vem sofrendo nas décadas recentes faz com que muitas famílias tenham restrição de recursos para seu bem-estar ou visando novos investimentos produtivos. Neste sentido, o PNHR é visto pelos agricultores, por lideranças rurais, e evidenciado neste estudo, como uma importante política social que se agrega como mais um componente de ações a serem trabalhadas para a promoção de um desenvolvimento rural integrado e sustentável. Muitas famílias beneficiadas pelo programa expressaram grande satisfação em realizar o sonho da construção ou reforma de sua casa. Isto provoca um forte efeito na autoestima das famílias, fortalecendo tanto o desejo de permanecer no espaço rural, como a expectativa de continuidade dos jovens na atividade. Este é um impacto importante, especialmente no contexto do estado de Santa Catarina, no qual as perspectivas de os filhos continuarem nas propriedades e atividades dos pais têm sido reduzidas contemporaneamente (ABRAMOVAY et al., 2001; AGUIAR, 2006).

Apesar dos avanços que o PNHR proporciona, foram verificados alguns limites para que ele cumpra os objetivos a que se propõe. Mesmo a microrregião em estudo sendo considerada um exemplo de avanço do Programa, verificou-se que a maioria das famílias que nele se inscreveram não foi contemplada. A não disponibilidade de recursos pelo Governo Federal, a falta de recursos dos agricultores para a contrapartida e o não enquadramento de alguns deles nas regras do Programa são os principais motivos que mantêm esta demanda reprimida. O novo formato do PNHR, proposto pelo decreto federal de abril de 2009, aponta caminhos para solução dos dois últimos limites antes citados, na medida em que amplia a faixa de subsídio e exige menos contrapartida das famílias mais vulneráveis socioeconomicamente. No entanto, a limitação de recursos liberados pelo Governo Federal foi o principal fator identificado para o não atendimento da demanda. Fica, portanto, a dúvida: o Governo Federal ampliará o volume de recursos para esta política social, especialmente agora que está previsto um maior desembolso de sua parte?

\section{Metodologia}

Para esta pesquisa, optou-se por estudar a implementação do PNHR em uma microrregião predominantemente rural, escolhendo quatro municípios do Oeste de Santa Catarina: Chapecó, Cordilheira Alta, Guatambu e Nova Itaberaba. A escolha recaiu sobre eles por se situarem em um território predominantemente rural, por serem municípios com diferentes tamanhos de população e indicadores socioeconômicos, bem como por estarem na área de atuação de uma cooperativa que atua com o PNHR, a Cooperativa de Crédito com Interação Solidária de Chapecó e Região (Cresol Chapecó) ${ }^{1}$.

A pesquisa utilizou concomitantemente a abordagem quantitativa e qualitativa. Foram levantados dados quantitativos sobre o programa na microrregião, bem como quantificadas diversas das respostas obtidas por perguntas objetivas formuladas a um conjunto de entrevistados. Com os mesmos entrevistados foram apresentadas perguntas abertas, cujas respostas discursivas foram avaliadas, qualitativamente, pela metodologia da análise de conteúdo (BAUER; GASKELL, 2003).

Nesses municípios, foi realizada uma pesquisa de campo entrevistando famílias inscritas no Programa, tenham sido elas beneficiadas ou não com a casa desejada, distribuindo os entrevistados conforme o número de inscritos por município. Entre abril e junho de 2009 foram, no total, realizadas 47 entrevistas, sendo 17 com famílias contempladas e $30 \mathrm{com}$ não contempladas pelo PNHR, conforme a propor- 
ção de cada caso e conforme o número de inscritos em cada município. Dessas, 21 foram realizadas em Chapecó, 11 em Nova Itaberaba, 9 em Guatambu e 6 em Cordilheira Alta. As entrevistas ocorreram com a presença do casal em exercício de chefia de cada família. Além disto, foram coletados documentos e realizadas entrevistas com dirigentes das principais organizações sociais e instituições que atuam com o Programa nestes municípios, quais sejam: a Cresol Chapecó, a Cooperativa de Habitação da Agricultura Familiar (Cooperhaf), a Associação dos Agricultores Familiares do Vale do Rio Uruguai (Aafvru), a Federação da Agricultura Familiar dos Três Estados do Sul (Fetraf-Sul), o Sindicato dos Trabalhadores na Agricultura Familiar de Chapecó e Região (Sintraf) e Prefeituras Municipais. Foram realizadas duas entrevistas adicionais, uma com a dirigente estadual e outra com o dirigente nacional da Cooperhaf, a qual faz a mediação entre o PNHR, o agente financeiro da Caixa Econômica Federal (CEF) e os agricultores familiares. Por fim, foi realizada uma revisão bibliográfica sobre a política social de habitação rural, bem como uma revisão sobre o funcionamento do PNHR entre 2003 e 2008, e sua reformulação em 2009. O novo formato do programa definido pelo Decreto Federal nº 6.819, de 13.04.2009 (BRASIL, 2009) está ainda em implantação, sem resultados consistentes que possam ser avaliados, motivo pelo qual o trabalho de campo versou sobre o período 2003-2008.

Este projeto foi submetido ao Comitê de Ética em Pesquisa com Seres Humanos da Universidade Comunitária da Região de Chapecó (Unochapecó), recebendo parecer favorável. Foi solicitado o consentimento livre e esclarecido dos sujeitos entrevistados, a partir de um termo de consentimento para esta publicação, devidamente assinado pelo pesquisado e pesquisadores. Assegurou-se a confidencialidade e a privacidade de seus depoimentos, garantindo a não utilização das informações em prejuízo dos que participassem da pesquisa e observando-se as normas legais e éticas para pesquisa que envolve seres humanos ${ }^{2}$.

\section{Organização cívica e políticas sociais nos territórios rurais}

O PNHR foi criado em 2003, com o objetivo principal de atender às famílias com renda entre um e três salários mínimos. Isto correspondia, em 2004, a $73,7 \%$ do total de domicílios rurais do país, o que se enquadra nos $85,2 \%$ dos estabelecimentos rurais brasileiros definidos como familiares (ESTATÍSTICAS, 2006). A renda média mensal domiciliar nos territórios rurais, no ano de 2004, foi de R $\$ 707$ para o país e de $\mathrm{R} \$ 1.035$ para a região Sul (ESTATÍSTICAS, 2006), situando-se está na faixa de 01 a 3 salários mínimos. Da agricultura familiar fazem parte agricultores in- seridos no mercado e com renda consistente e estável - a chamada agricultura familiar consolidada bem como um contingente expressivo de famílias com pouca renda - os denominados agricultores familiares periféricos ou em exclusão (FAO/INCRA, 1994). É a este público que se destinou prioritariamente o PNHR.

Em meados da década de 1990, inicia-se no Brasil um conjunto de políticas públicas visando trabalhar o desenvolvimento rural para além de seu caráter setorial produtivo - a agropecuária. Esses trabalhos partem de uma abordagem territorial, procurando integrar atores, setores e ações diversas que pudessem articuladamente promover o desenvolvimento rural. As primeiras iniciativas dessa abordagem foram exíguas, ganhando força somente a partir da década seguinte, em 2003. É nesse ano que, além da constituição do PNHR, há avanço em outras políticas sociais, como o Bolsa Família e a política dos Territórios Rurais ${ }^{3}$, que tiveram forte impacto sobre os territórios predominantemente rurais.

Historicamente, tanto os territórios predominantemente rurais quanto os agricultores em condições mais vulneráveis tiveram acesso restrito a serviços públicos.

Até meados da década de 1990, as políticas e serviços públicos para os territórios rurais tinham uma orientação claramente setorial, focada na produção agropecuária. Em termos gerais, as políticas eram direcionadas para os territórios com maior concentração populacional (ROVER, 2007). Em 1982, Silva(1982) denominava a isso de modelo de desenvolvimento urbano-industrial, por beneficiar municípios e regiões com maior concentração urbana e industrial, deixando os territórios predominantemente rurais à margem de muitas políticas e serviços públicos, gerando um ciclo vicioso que prejudicou seu desenvolvimento.

Por esse desenrolar, o acesso a muitos serviços públicos e infraestruturas sociais e produtivas ainda é mais restrito para os territórios mais rurais, como se pode verificar nos já citados casos do acesso à telefonia, à internet, a condições de transporte, água encanada, entre outros. Para o caso da moradia, merece destaque estudo recente (LAC, 2002, p. 3) no qual a percepção de $43,6 \%$ das famílias rurais catarinenses é de que o estado de conservação de sua residência estava entre regular e ruim. Para as famílias agricultoras da região de Chapecó, esta percepção chega a mais de $46 \%$.

A construção de políticas que transcendem a dimensão produtiva, bem como o avanço para políticas sociais mais efetivas para os territórios rurais, não se deu apenas por iniciativa institucional - estatal. Com a democratização do país e a nova Constituição Federal de 1988, novos espaços de participação social e política se constituíram. Os "movimentos sociais do campo" tiveram um papel central para gerar novas pautas para as políticas de desenvolvimento ru- 
ral (MEDEIROS, 1997). O Estado vem respondendo a algumas demandas sociais, garantindo o direito à aposentadoria especial para os/as agricultores/as, o reconhecimento do trabalho da mulher agricultora, bem como outros benefícios, como o salário maternidade e a aposentadoria por invalidez. Também o Programa Nacional de Fortalecimento da Agricultura Familiar (Pronaf) 4 é uma resposta das políticas públicas a uma demanda apresentada há anos pelos agricultores familiares através da Confederação Nacional dos Trabalhadores da Agricultura (Contag) e do Departamento Nacional de Trabalhadores Rurais da Central Única dos Trabalhadores (DNTR/CUT) (SCHNEIDER; CAZELLA; MATTEI, 2004). Assim também aconteceu com a política nacional de habitação rural, instituída através do PNHR.

\section{Breve descrição do Programa Nacional de Habitação Rural (PNHR)}

O PNHR iniciou em 2003 com três modalidades de contratos:

a) Programa de Subsídio à Habitação de Interesse Social (PSH);

b) Carta de Crédito com Operações Coletivas FGTS (CCFGTS); e

c) Crédito Solidário (FDS).

Além disso, a modalidade CCFGTS divide-se em dois tipos: a) para o agricultor cuja renda mensal é até um salário mínimo, o subsídio é de $\mathrm{R} \$ 5.907$, ficando o restante da obra sob sua responsabilidade;

b) para o agricultor cuja renda mensal seja maior que $\mathrm{R} \$ 930$ e menor que $\mathrm{R} \$ 1.500$, o subsídio é de R \$ 3.000, sendo que o restante poderá ser financiado em até 96 meses, confome Quadro 1.

Esta formatação do programa funcionou até 2009, quando, através do Decreto Federal n. 6.819, novas regras foram instituídas. As novas regras apresentam mudanças significativas, que se propõem a superar a principal dificuldade para os agricultores com maior vulnerabilidade socioeconômica acessarem o PNHR: a exigência de contrapartidas financeiras.

A nova formatação do PNHR prevê que os seus beneficiários serão os agricultores familiares divididos em três grupos:

a) Grupo 1: agricultores com renda anual de até R\$ 10.000 para os quais o valor liberado será de $R$ \$ 10.000, dos quais o mutuário pagará apenas os juros, totalizando $\mathrm{R} \$ 350$, tendo assim um subsídio de $\mathrm{R} \$ 10.000$.

b) Grupo 2: agricultores com renda anual de $\mathrm{R} \$$ 10.000 a $\mathrm{R} \$ 22.000$, para os quais o limite de recursos acessado é de $\mathrm{R} \$ 29.000$, com subsídio de $\mathrm{R} \$$ 7.000. O restante deverá ser pago em dez anos com taxa de juros de $5 \%$ ao ano mais taxa de juros referencial (TR), em parcelas mensais.

\section{Quadro 1 - Modalidades de contratos do PNHR entre 2003 e 2009}

\begin{tabular}{|c|c|c|c|}
\hline Programa PSH & $\begin{array}{l}\text { Programa CCFGTS } \\
\text { Operações Coletivas } \\
\end{array}$ & $\begin{array}{l}\text { Programa CCFGTS } \\
\text { Operações Coletivas } \\
\end{array}$ & $\begin{array}{l}\text { Programa Crédito } \\
\text { Solidário }\end{array}$ \\
\hline $\begin{array}{l}\text { Modalidade: Leilão } \\
\text { Subsidiado }\end{array}$ & $\begin{array}{l}\text { Modalidade: Caução } \\
\text { (fundo perdido) }\end{array}$ & $\begin{array}{l}\text { Modalidade: } \\
\text { Financiamento }\end{array}$ & $\begin{array}{l}\text { Modalidade: } \\
\text { Financiamento }\end{array}$ \\
\hline $\begin{array}{l}\text { Recurso: variam entre } \mathrm{R} \$ \\
2.000 \text { e } \mathrm{R} \$ 4.500 \text { (por famí- } \\
\text { lia) }\end{array}$ & $\begin{array}{l}\text { Recursos : R\$ } 5.907 \\
\text { (subsidiado) }\end{array}$ & $\begin{array}{l}\text { Recursos: R\$ } 3.000 \\
\text { (subsidiado) }\end{array}$ & $\begin{array}{l}\text { Recursos: R\$ } 10.000 \mathrm{p} / \\
\text { construção e R\$ } 7.500 \mathrm{p} / \\
\text { reforma }\end{array}$ \\
\hline $\begin{array}{l}\text { Contrapartida oferecida por } \\
\text { municípios ou estados, que } \\
\text { poderá ou não ser cobrada } \\
\text { dos beneficiários }\end{array}$ & Contrapartida: $\mathrm{R} \$ 2.093$ & Financiado: $\mathrm{R} \$ 6.000$ & $\begin{array}{l}\text { Contrapartida: Não há, por- } \\
\text { tanto o recurso é todo finan- } \\
\text { ciado diferindo do CCFGTS. }\end{array}$ \\
\hline $\begin{array}{l}\text { Publico Alvo: agricultores } \\
\text { com renda até } \mathrm{R} \$ 465 \text { men- } \\
\text { sais }\end{array}$ & $\begin{array}{l}\text { Público alvo: agricultores } \\
\text { com renda até um salário } \\
\text { mínimo }\end{array}$ & $\begin{array}{l}\text { Público alvo: agricultores } \\
\text { com renda de } \mathrm{R} \$ 930 \text { a } \mathrm{R} \$ \\
1.500\end{array}$ & $\begin{array}{l}\text { Público alvo: agricultores } \\
\text { com renda até três salários } \\
\text { mínimos }\end{array}$ \\
\hline $\begin{array}{l}\text { Prazo de devolução: varia } \\
\text { conforme proposta da enti- } \\
\text { dade promotora, até } 72 \text { me- } \\
\text { ses. }\end{array}$ & $\begin{array}{l}\text { Prazo de devolução: não há } \\
\text { devolução }\end{array}$ & $\begin{array}{l}\text { Prazo de devolução: até } 96 \\
\text { meses }\end{array}$ & $\begin{array}{l}\text { Prazo de devolução: até } 240 \\
\text { meses }\end{array}$ \\
\hline $\begin{array}{l}\text { Fonte dos recursos: Banco } \\
\text { Central do Brasil }\end{array}$ & Fonte dos recursos: FGTS & Fonte dos recursos: FGTS & Fonte dos Recursos: FDS \\
\hline
\end{tabular}

Fonte: Munarini (2009). 
c) Grupo 3: agricultores familiares com renda anual de $\mathrm{R} \$ 22.000$ a $\mathrm{R} \$ 60.000$, para os quais o limite de recursos liberados é de $\mathrm{R} \$ 70.000$, sem subsídio. O pagamento deverá ser feito em dez anos com juros que variam de 5,6 a $8,16 \%$ mais TR, conforme o valor financiado, também com prestações mensais.

O novo PNHR estabelece as categorias de agricultores beneficiários conforme as regras do Pronaf. Isso agiliza processos e aproveita toda uma sistemática consolidada há anos para distribuição das categorias de agricultores. Esse tipo de proposta vinha sendo defendido há tempos pelas organizações dos agricultores familiares e também por estudiosos do assunto (SILVESTRO et al., 2001). No entanto, o novo formato do PNHR, que está sendo posto em funcionamento desde 2009, ainda não permite avaliações mais consistentes de sua implementação.

Para buscar avaliar seu potencial e prováveis limitações, apresenta-se a seguir uma discussão e uma análise da implementação do programa entre 2003 e o início de 2009, a partir do estudo realizado junto a quatro municípios do Oeste Catarinense, região com amplo predomínio da agricultura familiar e que concentra grande número de inscritos e beneficiários.

\section{Análise de um caso: o PNHR em um terri- tório predominantemente rural catarinense}

A experiência do PNHR demonstrou um efeito positivo com o envolvimento de vários setores da sociedade em sua execução. Nos municípios estudados, as instituições e organizações envolvidas com o Programa foram a Caixa Econômica Federal (CEF), que é a gestora do Programa, em parceria com as entidades executoras: Sintrafs, Cresol, Cooperhaf, Associação do Rio Uruguai, Prefeituras e Fetaesc. As diferentes entidades e organizações sociais envolvidas na implantação da política permitiram que as informações e os projetos ficassem mais acessíveis e simplificados aos agricultores.

A CEF não disponibiliza estrutura pessoal e técnica para chegar até as famílias no meio rural, enquanto as associações, cooperativas e Sintrafs conhecem melhor a realidade das famílias e com facilidade realizam trabalhos de campo como: o cadastro de informações sobre a família que está solicitando o recurso, a análise de seu enquadramento às regras do programa, além do encaminhamento da proposta para uma equipe de engenharia para elaborar o projeto técnico. Após ser elaborado, o projeto técnico é entregue à $\mathrm{CEF}$ que fará análise do mesmo, bem como de toda documentação individual de cada beneficiário e do cônjuge (quando houver). Após análise e aprovação, havendo recursos, a CEF marca a data da assinatura dos contratos, liberando o início da obra que tem um prazo máximo de quatro meses para execução.

A parceria entre instituições de Estado, agente financeiro e organizações sociais traz muitos resultados na experiência do PNHR. Segundo o Jornal da Caixa, a organização social e a capacidade de dar contrapartidas são as principais explicações para a concentração das ações do Programa nos três estados do Sul do Brasil. O jornal afirma que entre 2003 e 2006 foram assinados mais de 17 mil contratos beneficiando as famílias agricultoras do meio rural no Brasil, com mais de R\$ 140 milhões, dos quais a maioria beneficiou agricultores familiares da Região Sul (JORNAL DA CAIXA, 2009). Também os agricultores que foram entrevistados afirmam que é central o papel das organizações sociais que operam o Programa, na medida em que elas "simplificam e encaminham os processos junto ao banco". O fato de a Região Sul possuir o maior percentual de municípios com Conselho Municipal de Habitação (IBGE, 2008, p. 251) é um fator adicional que permite qualificar a atuação das organizações sociais, na medida em que elas se informam e conhecem os procedimentos relativos ao andamento desse programa.

Nos quatro municípios estudados, foram identificadas 863 famílias demandantes por reforma ou construção de casa nova pelo PNHR, no período entre 2003 a 2008. Deste total, $314(36,4 \%)$ foram contemplados e $549(63,6 \%)$ estão na fila de espera. O grande número de inscritos demonstra a histórica falta de um programa rural de inclusão habitacional. $\mathrm{O}$ grande número de não contemplados é explicado pelas entidades operadoras e pelos agricultores entrevistados através de três principais fatores:

a) a não disponibilização de recursos financeiros por parte do Governo Federal e da Caixa como agente financeiro responsável;

b) o não enquadramento entre a renda familiar e a modalidade do programa demandada pela família;

c) a falta ou dificuldade de muitas famílias conseguirem os recursos necessários para a contrapartida exigida pelo PNHR.

A falta de recursos por parte do Governo Federal e da Caixa chegou a provocar uma atitude das organizações executoras de realizar sorteios para evitar discriminação na seleção dentre aquelas famílias que poderiam fornecer a contrapartida. Para as demais famílias, com dificuldades de oferecer a contrapartida exigida, resta aguardar a implantação do novo formato do Programa a partir de 2009 , na expectativa de que o governo disponibilize maior volume financeiro.

Quanto ao não enquadramento entre a renda familiar e a modalidade do Programa demandada pela família, muitas delas não apresentam renda compatível com as obrigações exigidas pelo PNHR. O novo formato do Programa tem como um de seus objeti- 
vos contemplar as famílias que se encontraram até então excluídas pelas excessivas exigências, além de facilitar para os que não dispõem da contrapartida.

Quanto à contrapartida, 74\% dos entrevistados, independentemente de terem feito a obra ou estarem na fila de espera, afirmam que não tinham ou não têm a contrapartida disponível.

Dentre os que já foram contemplados, verificouse que a maioria teve muitas dificuldades para concluir a obra, apesar de ter conseguido parte do recurso a fundo perdido. Para a maioria, o volume de recursos disponibilizado pelo Programa, somado à sua contrapartida, não foi suficiente para realizar toda a obra. Muitos deles tiveram que complementar os recursos com vendas de bens da propriedade ou mesmo buscando empréstimo de familiares, amigos ou bancário. A falta de recursos financeiros, nesse sentido, é apontada como a principal dificuldade dos que foram beneficiados pelo Programa para concluírem a obra. Como os valores máximos das obras para casas novas giram em torno de $\mathrm{R} \$ 15$ mil, fica evidente a descapitalização em que se encontram os agricultores familiares que se beneficiaram do PNHR. Para se ter uma ideia da condição anterior de suas moradias, o que pode ser considerado um indicador de seu grau de descapitalização, mais de $78 \%$ do total de entrevistados afirmou que sua casa se encontrava em situação ruim ou inabitável.

Comparando-se com os dados da percepção dos produtores, quanto ao estado de conservação da sua residência, obtidos pelo LAC (2002,

p. 3), verificamos que este Programa de habitação está atingindo um forte percentual de produtores que percebiam como ruim a condição de sua morada. Apesar dessa condição, os que já fizeram a casa ou reforma afirmam que "deram um jeito", vendendo alguma coisa da propriedade ou emprestando para não perder a oportunidade. Os que ainda não foram contemplados afirmam estar planejando como "arrumar o dinheiro", para não ficar de fora do Programa.

Além da dificuldade de dispor do pouco recurso exigido como contrapartida, mais de $74 \%$ dos entrevistados afirmaram que em função da pouca renda familiar, se não houvesse o subsídio estatal não teriam como construir ou reformar sua casa.
Nesse sentido, o PNHR atua como uma política social que permite a um conjunto de famílias rurais terem o estímulo da casa nova ou reformada, para permanecerem nos territórios rurais. Essas dificuldades expressadas por quem já fez sua obra, bem como o número dos não contemplados por limitações de contrapartida, faz imaginar que o novo formato do Programa, para implementação a partir de 2009, com mais subsídio, permitirá que maior número dos agricultores mais vulneráveis possam acessá-lo.

No entanto, reiteramos que a pouca disponibilização de recursos por parte do Governo $\mathrm{Fe}$ deral foi o principal motivo apresentado para que o Programa não atendesse a todos os inscritos até o ano de 2008. Fica, portanto, a dúvida se os maiores subsídios governamentais previstos no novo formato do programa instituído pelo decreto de abril de 2009 serão de fato implementados.

A necessidade de melhorar as condições de moradia, a perspectiva de continuar vivendo no espaço rural e o interesse em incentivar os filhos a permanecerem na agricultura, são os principais pontos que levam $100 \%$ dos entrevistados a valorizar a política de habitação rural e a considerar que ela se torne permanente. Porém, assim como não basta apenas gerar renda para os agricultores, o PNHR não é suficiente para garantir a permanência do agricultor familiar no campo.

Todos os entrevistados apontam outras ações por parte dos governos, para compensar a histórica depreciação dos territórios rurais em relação aos urbanos. Há várias políticas públicas que até existem, mas muitas vezes não chegam a muitas das famílias, especialmente as mais vulneráveis.

Conforme verificado por outros estudos (ROVER et al., 2008, 2009), também observou-se que a principal demanda de política pública da maioria dos agricultores dos quatro municípios (67\% dos entrevistados) diz respeito ao maior acesso à assistência técnica. É uma evidência de que, além da qualidade de vida proporcionada pela nova habitação, os agricultores querem assistência técnica para qualificarem a sua produção, em busca de melhor renda monetária e condições para sua subsistência.

Além da política de habitação e da assistência técnica, os agricultores ainda citaram a garantia de renda, a melhoria das infraestruturas das proprieda- 
des e o acesso à rede de água como suas principais necessidades atuais. Essas respostas destacam a necessidade de ampliar a intersetorialidade e interinstitucionalidade das políticas e das ações para o desenvolvimento rural, visando superar seu viés histórico que concentra as ações públicas no setor agropecuário. Neste sentido, uma abordagem territorial e de ações integradas para a promoção do desenvolvimento rural deve ser reforçada.

$\mathrm{Na}$ perspectiva de integrar ações e políticas, o PNHR propõe outras atividades além da viabilização da moradia, às quais denomina de trabalhos sociais, que são desenvolvidos por equipes de assistência social das entidades executoras. Os trabalhos sociais se referem basicamente a ações de formação (palestras, oficinas e dias de campo) em planejamento e embelezamento das propriedades, cooperativismo e associativismo, produção de subsistência (horta, pomar, e animais domésticos), reciclagem do lixo e saneamento básico. Eles visam promover um processo educacional que oriente para propostas sustentáveis e articule diferentes dimensões do desenvolvimento rural. Dos agricultores dos quatro municípios estudados, $63,8 \%$ consideram importantes os trabalhos sociais, demonstrando que este complemento à política social da habitação rural tem boa aceitação.

Por fim, destaca-se que nos quatro municípios estudados foi o Programa CCFGTS, modalidade Caução, o mais acessado pelos agricultores, o que corresponde a mais de $63 \%$ dos casos. Isso se deve à especificidade da modalidade (Quadro 1), especialmente quanto à relação entre as normas de enquadramento e à realidade das famílias contempladas. O subsídio previsto de $\mathrm{R} \$ 5.907$, a renda máxima declarada pela família de um salário mínimo mensal e a necessidade de se organizar em grupos para participar desta modalidade são os principais fatores que explicam porque ela é a mais acessada. Nos primeiros dois fatores é o perfil de renda dos agricultores e a sua expectativa de acessar o subsídio que explicam o porquê da preponderância desta modalidade. No terceiro fator, a organização social dos agricultores familiares é determinante, já que para acessar a modalidade há a exigência da organização em grupo. Nesse caso, o PNHR criou uma exigência para estimular a organização coletiva dos mutuários, à qual as organizações da agricultura familiar responderam e, assim, puderam beneficiar seu público de atuação. Através da fala da dirigente estadual da Cooperhaf, pode-se verificar que as organizações ligadas aos agricultores familiares da região estão atentas para a necessidade de sua organização:

Agora nós temos a questão do 'Minha Casa, Minha Vida', que é um programa excelente do governo, porém nós temos que nos fazer presente para que os recursos também cheguem para a agricultu- ra familiar, senão o que acontece é que vai para os grandes centros urbanos, para as regiões metropolitanas. $^{5}$

A expressão de quem coordena uma organização social que se relaciona diretamente com uma política pública federal corrobora o ponto de vista manifestado por Sen (2000, p. 184) de que "Em uma democracia o povo tende a conseguir o que exige e, de um modo mais crucial, normalmente não consegue o que não exige."

\section{Considerações finais}

A constituição e o funcionamento atual do PNHR são devedores da dinâmica das organizações sociais envolvidas. Além de o Programa ter sido constituído a partir de demanda das organizações dos agricultores familiares, o seu papel é apontado como determinante dos resultados superiores de famílias atendidas e de recursos mobilizados no Sul do Brasil, quando comparados com outras regiões (JORNAL DA CAIXA, 2009) $)^{6}$.

O papel da gestão e do controle social para o resultado das políticas públicas tem um longo histórico de discussão e estudos, a ponto que no ano de 2009 o controle social está no título da VII Conferência Nacional de Assistência Social ${ }^{7}$. Dworkin (1977) e Sejersted (1993), citados por Reis (2004, p. 75), identificaram em seus estudos "melhores condições para a deliberação democrática efetiva [...] se darmos representação apropriada aos interesses e identidades afetados pelas decisões." O PNHR não é uma instância de deliberação sobre as políticas públicas, mas é possível estabelecer um paralelo entre a sua dinâmica organizativa e a importância de se dar "representação apropriada aos interesses e identidades afetados pelas decisões". No caso aqui estudado, mais do que representação apropriada, as organizações dos agricultores familiares realizaram a gestão da operacionalização do Programa. Verificou-se que o Governo Federal teve interesse no envolvimento de outros atores sociais como as cooperativas, prefeituras e associações, e que isso foi responsável por dar mais eficiência ou para promover um maior controle social da aplicação da política. A parceria da CEF com o Sintraf, Cooperhaf, Cresol e Aafvru foi determinante no cadastramento de famílias, na elaboração dos projetos, na execução e no acompanhamento das obras. O envolvimento de atores presentes no dia a dia das famílias rurais permitiu uma ampliação dos resultados, proporcionando maior eficiência e efetividade da política social.

O PNHR proporcionou um impacto positivo no espaço rural, tanto econômico quanto social, dando uma nova perspectiva para as famílias ali permanecerem. Apesar de ser uma política importante, a to- 
talidade das famílias afirma que a habitação de qualidade não é suficiente para manter o agricultor familiar nos territórios rurais. Existe um empenho por parte dos agricultores em permanecer na atividade e para que seus filhos permaneçam (HAHN, 2009), mas se fazem necessárias outras políticas para que isso aconteça. Do ponto de vista das famílias, haveria de se garantir o acesso à assistência técnica e à renda, $\mathrm{o}$ melhoramento das estruturas das propriedades, o rebaixamento dos custos de produção, entre outros. Apesar de muitas ações e políticas neste sentido já existirem, as famílias de agricultores estudadas, que são as mais vulneráveis socioeconomicamente, não têm acesso a elas ou o tem de forma muito restrita.

Mais de 63\% das famílias inscritas no PNHR não foram contempladas. A revisão do Programa, através do Decreto Federal de abril de 2009, aponta para a solução dessas limitações. Caberá verificar se, nos tempos vindouros da implementação desta necessária política social, os recursos disponibilizados pelo governo e seus agentes não continuarão sendo fator de impedimento de maior avanço, visto que até 2008 havia um subsídio proposto bem menor e mesmo assim muitos recursos não foram disponibilizados.

Morar bem está diretamente relacionado a uma nova perspectiva de vida para os habitantes dos territórios rurais. Esse bem-estar se potencializa quando a política permite que o beneficiário se sinta parte do conjunto de atores que, com diferentes papéis, proporciona a execução desses benefícios sociais. $\mathrm{O}$ PNHR demonstrou que, apesar das dificuldades de parte dos agricultores para realizar o projeto da nova morada, os beneficiados não esconderam a satisfação de melhorar sua qualidade de vida com a reforma ou construção da casa, favorecendo sua autoestima e o prazer de viver no meio rural.

\section{Referências}

ABRAMOVAY, R. et al. Os impasses sociais da sucessão hereditária na agricultura familiar. Florianópolis: Epagri; Brasília: NEAD/Ministério do Desenvolvimento Agrário, 2001.

AGUIAR, F. L. de. Juventudes de um rural catarinense: trajetórias cotidianas no contexto da agricultura familiar. 2006. 141 p. Dissertação (Mestrado em Educação) Universidade Federal de Santa Catarina, Florianópolis, 2006.

BAUER, M. W.; GASKELL, G. (Ed.). Pesquisa qualitativa com texto, imagem e som: um manual prático. Petrópolis: Vozes, 2003.

BRASIL. Decreto Federal n. 6.819 de 13 de abril de 2009. Diário Oficial da República Federativa do Brasil.
Edição Extra, ano CXLVI n. 69-A, seção 1, p. 1, Brasília, 13 abr. 2009.

ESTATÍSTICAS do meio rural. Departamento Intersindical de Estatística e Estudos Socioeconômicos. Núcleo de Estudos Agrários e Desenvolvimento Rural. Brasília: MDA: DIEESE, 2006.

FAO/INCRA. Diretrizes de política agrária e desenvolvimento sustentável. Brasília: FAO/INCRA, 1994.

HAHN, M. Pluriatividade e meio ambiente na agricultura familiar de Itapiranga/SC. 2009. 110 p. Dissertação (Mestrado em Ciências Ambientais) - Universidade Comunitária Regional de Chapecó, Chapecó, 2009.

IBGE - Instituto Brasileiro de Geografia e Estatísticas. Perfil dos municípios brasileiros 2008. Rio de Janeiro: IBGE, 2008.

JORNAL DA CAIXA. Caixa assina contrato n. $4.000 \mathrm{na}$ agricultura familiar. Disponível em: <http:// www.caixa.com.br/>. Acesso em: 23 jan. 2009.

LAC-Levantamento Agropecuário Catarinense. 2002. Disponível em: <http://www.cepa.epagri.sc.gov.br/ Dados_do_LAC>.Acesso em: 15 jun. 2009.

MDS, Ministério do Desenvolvimento Social e Combate à Fome. VII Conferência Nacional de Assistência Social. Disponível em: <http://www.mds.gov.br/cnas〉. Acesso em: 08 out. 2009.

MEDEIROS, L. S. de. Trabalhadores rurais, agricultura familiar e organização sindical. São Paulo em Perspectiva, v. 11, n. 2, p. 65-72, 1997.

MOSER, L.; FORCHESATTO, R. Problematizando a implementação e gestão do programa Bolsa Família em municípios do Oeste de Santa Catarina. In: ENCONTRO NACIONAL DE PESQUISADORES EM SERVIÇO SOCIAL, 11. São Luís. Anais ... São Luís, Maranhão: Editora ABEPSS, 2008. 1 CD ROM.

MUNARINI, P. R. A política de habitação rural brasileira e o desenvolvimento da agricultura familiar no oeste catarinense. 2009. 71 p. Monografia (Curso de Agronomia) - Universidade Comunitária Regional de Chapecó, Chapecó, 2009.

REIS, F. W. Deliberação, interesse e 'sociedade civil'. In: COELHO, V. S. P.; NOBRE, M. (Org.). Participação e deliberação: teoria democrática e experiências institucionais no Brasil contemporâneo. São Paulo: Ed. 34, 2004, p. 63-92.

ROVER, O. J. Desenvolvimento local em territórios rurais: análise de políticas federais no período 1994-2005. In: 
ENCONTRO ANUAL DAANPOCS, 30, Caxambu. Anais... Caxambu, Minas Gerais, 2006.

Redes de poder e governança local: análise da gestão político administrativa em três fóruns de desenvolvimento com atuação na região Oeste de Santa Catarina. 2007. 253 p. Tese (Doutorado em Desenvolvimento Rural) - Universidade Federal do Rio Grande do Sul, Porto Alegre, 2007.

. et al. Estudo da realidade rural do município de Pinhalzinho: diagnóstico e projeções. Relatório da disciplina Estudo da realidade Rural do curso de Agronomia. Unochapecó: Chapecó, 2008. Fotocopiado.

. et al. Estudo da realidade rural do município de Xaxim: diagnóstico e projeções. Relatório da disciplina Estudo da realidade Rural do curso de Agronomia. Unochapecó: Chapecó, 2009. Fotocopiado.

SCHNEIDER, S.; CAZELLA, A. A.; MATTEI, L. Histórico, caracterização e dinâmica recente do Pronaf - Programa Nacional de Fortalecimento da Agricultura Familiar. In: SCHNEIDER, S.; SILVA, M. K.; MARQUES, P. E. M. (Org.). Políticas públicas e participação social no Brasil rural. Porto Alegre: Ed. da UFRGS, 2004. p. 21-49. (Série Estudos Rurais).

SEN, A. Desenvolvimento como liberdade. São Paulo: Companhia das Letras, 2000.

SILVA, J. G. da. A modernização dolorosa: estrutura agrária, fronteira agrícola e trabalhadores rurais no Brasil. Rio de Janeiro: Jorge Zahar, 1982.

SILVESTRO, M. et al. Os impasses sociais da sucessão hereditária na agricultura familiar. Florianópolis: Epagri, Brasília: NEAD, 2001.

\section{Notas}

1 A Cresol Chapecó integra uma rede de organizações da agricultura familiar que, para atuar com esta política social, compõe-se da Federação da Agricultura Familiar dos Três Estados do Sul (Fetraf-Sul) e seus sindicatos, bem como da Cooperativa de Habitação da Agricultura Familiar (Cooperhaf), criada pelaFetraf-Sul para atuar especificamente com este tema e com esta política.

2 Esta pesquisa cumpriu todos os princípios e procedimentos éticos em sua organização metodológica. Os procedimentos respeitaram as Resoluções n. 196 e n. 251 do Conselho Nacional de Saúde. O trabalho foi submetido ao Comitê de Ética em Pesquisa da Unochapecó, tendo sido aprovado sob registro n. 098/09.
3 O programa Bolsa Família é um programa amplamente conhecido, que se constitui numa política pública de garantia de renda a famílias em condições de grande vulnerabilidade socioeconômica(MOSER;FORCHESATTO, 2008).Apolítica dos Territórios Rurais é uma ação que tem início comoPronaf Infra-Estrutura e Serviços Municipais, criado em 1997, com objetivo de ampliar as infraestruturas sociais e econômicas dos municípios predominantemente rurais. Esta política ganhou um caráter microrregional a partir de 2003, com uma Secretaria do Ministério do Desenvolvimento Agrário especificamente para este fim - a Secretaria de Desenvolvimento Territorial (SDT/MDA). Para maiores informações sobre o avanço de políticas de abordagem territorial para os espaços rurais, ver Rover (2006).

4 O principal foco do Pronaf é a oferta de crédito rural. Ele se inicia com modalidades de crédito produtivo para os agricultores familiares, em geral. Como passar do tempo veio a se compor de várias modalidades como Pronaf Mulher, Pronaf Jovem, Pronaf Agroecologia, entre outros. Com essas modalidades, estabelecem-se diferenciações de públicos e de ênfases para o desenvolvimento da agricultura familiar, explicitando a necessidade de trabalhar o desenvolvimento rural integrando diferentes focos e setores.

5 Os autores agradecem o apoio de Francieli de Cesaro, estudante de psicologia da Unochapecó, que através de outra pesquisa relacionada a esta, sob coordenação de um dos autores, contribuiu na realização de entrevistas com alguns dirigentes de organizações dos agricultores.

6 Por outro lado, é também importante pesar o fato de que, mesmo os agricultores familiares em condições mais vulneráveis do Sul do Brasil, são muitas vezes mais estruturados que aqueles do Norte e Nordeste, especialmente.

7 O tema desta conferência é "Participação e controle social noSUAS"'(MDS, 2009).

\section{Oscar José Rover}

oscar.rover@gmail.com

Doutorado em Desenvolvimento Rural pela Universidade Federal do Rio Grande do Sul (Ufrgs)

Professor do Departamento de Zootecnica e Desenvolvimento Rural daUniversidade Federal de Santa Catarina (UFSC)

\section{UFSC - CCA}

Campus Universitário Reitor João David Ferreira Lima

Bairro Trindade

Florianópolis - Santa Catarina

CEP: 88010-970 
Paulo Roberto Munarini

p.papau@unochapeco.edu.br

Agrônomo formado pela Universidade Comunitária

da Região de Chapecó (Unochapecó)

Agricultor orgâncio

Vice-presidente da Cooperativa de Crédito com

Interação Solidária de Chapecó (Cresol, Chapecó)

\section{Cresol Chapecó}

Rua Clevelândia, 315D

Centro

Chapecó - Santa Catarina

CEP: 89809-000 